\title{
Effects of As Cast Holes on Cooling Patterns in Directional Solidification of Plate Castings
}

\author{
Ikuzo Goto* and Setsuo Aso \\ Department of Materials Science, Graduate School of Engineering Science, Akita University, Akita 010-8502, Japan
}

The directional solidification characteristics and generation patterns of isolated pools of liquid metal in plate castings with as cast holes were numerically examined, and fundamental concepts for the casting design, including the holes, were also investigated. For the as cast hole effects $H / T$ ( $H$ : as cast hole effective range, $T$ : plate thickness), there were differences depending on the hole size as well as the casting and mold materials, which reflect the directional solidification characteristics associated with the cooling effects due to the hole. For the finite-width plate castings with as cast holes, isolated liquid pools occurred at locations between a hole and an end face or between the holes under specific conditions. The generation status of isolated liquid pools indicated that the conditions with larger values of the difference between the end and as cast hole effects $(E-H) / T$ ( $E$ : end-effective range) in the range of 1.8-5.3 are preferable for preventing the generation of isolated liquid pools. Therefore, the consideration of $(E-H) / T$ is useful for the casting design. In addition, the generation of isolated liquid pools could be prevented by the appropriate use of chills. Moreover, the generation was sometimes prevented by a temperature decrease of the melt during mold filling. The success of these techniques in preventing shrinkage defects was experimentally confirmed. [doi:10.2320/matertrans.F-M2016840]

(Received July 21, 2016; Accepted December 2, 2016; Published January 20, 2017)

Keywords: as cast hole, cooling effect, directional solidification, casting design, CAE

\section{Introduction}

As cast holes, that is, the holes formed by molds or cores in casting processes, enable not only near-net-shape manufacture but fewer machining processes and higher material yields. For example, several as cast holes are often utilized as bolt holes for crimp terminals and branched sleeves for electric wire connections, which are manufactured by casting processes using pure copper or pure aluminum. In particular, square as cast holes are sometimes used for cup-head squareneck bolts. The as cast holes are also used in semisolid die casting processes of aluminum alloys, because of less effects of both heating and solidification shrinkage on core pins than those in a conventional die casting process. Recently, a study of expendable carbon cores for complexly shaped unmachinable holes was conducted. ${ }^{1)}$ Water-soluble salt cores are also available for these applications. ${ }^{2}$ )

As a general rule, it has been observed that, beyond a certain depth, as cast holes with smaller diameters are difficult to cast in gravity-casting processes for cast iron or steel as well as in die casting processes. ${ }^{3)}$ In these cases, burn on the molds tend to occur because of the temperature increase in the cores, making shake-out or sand stripping difficult. Furthermore, for conventional die casting processes, a frequent exchange of thinner core pins is needed because of bending or breaking due to thermal and solidification shrinkage or burn on, which means that machining processes are a more practical way to form the holes. ${ }^{4)}$ For semisolid die casting processes, most of these problems have been solved. However, there are few reports about the cooling and solidification patterns of castings including as cast holes, even though the generation of shrinkage defects may be assisted by the holes. ${ }^{3,5)}$ The understanding of such patterns is valuable for the application of as cast holes because it not only reduces trial and error but also saves design costs. In this study, the effects of the cooling patterns of as cast holes on the directional solidification characteristics

*Corresponding author, E-mail: goto@gipc.akita-u.ac.jp of castings were examined, and fundamental concepts for casting design including holes were also investigated.

\section{Numerical and Experimental Method}

\subsection{Heat transfer and solidification simulation}

Three-dimensional heat transfer and solidification simulation was performed with commercial software, ADSTEFAN (Hitachi Industry \& Control Solutions, Ltd.). Figure 1 shows four simplified simulation objects which consist of plate castings with as cast holes and an end face, and Fig. 2 shows the four corresponding models. For the model shown in Fig. 2(d), an industrial, functional shape such as that used in crimp terminals was assumed. In the simulation, square as cast holes were modeled, and circular holes were also modeled as shown in Fig. 2(a); for the round holes, the diameter, $D$, had to be large enough to facilitate the shape reproduction by the computational elements. Items such as the draft angle, water cooling of the cores, all parting planes, sprue and risers were not
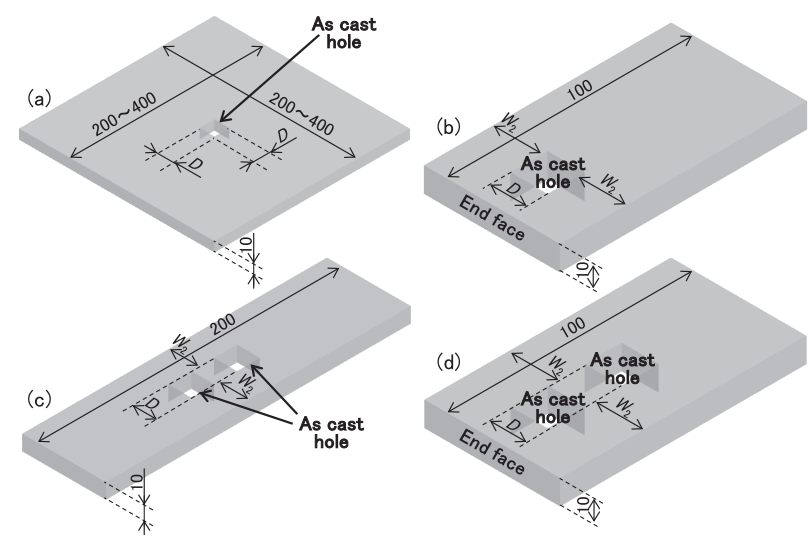

Fig. 1 Schematic view of overall simulation objects. (a) infinite plate casting with an as cast hole, (b) finite width plate casting with an as cast hole and an end face, (c) finite width plate casting with two as cast holes and (d) finite width plate casting with two as cast holes and an end face. 
considered. Based on the geometric symmetry, 1/4- or 1/8-symmetric 3-dimensional models were employed as shown in Fig. 2. The thickness of all plate castings was assumed to be $T / 2=5 \mathrm{~mm}$, and the mold thickness was $40 \mathrm{~mm}$ from the outer surface of the castings. The hole size $D$, and the plate widths $W_{1}$ and $W_{2}$ from the ends or the sides to the edges of the holes were varied. All computational elements were set to be cubic with dimensions of $0.5 \mathrm{~mm}$ on each side.

Table 1 shows the physical properties ${ }^{6-9)}$ and initial temperatures of the casting and mold materials used in the simulation. The latent heat was uniformly distributed over the temperature range between the liquidus and solidus temperatures. For convenience, for the pure metals, the solidus temperature was set to $1 \mathrm{~K}$ below the liquidus temperature on the basis of previous studies. ${ }^{10-12)}$ The initial superheat of all casting ele-
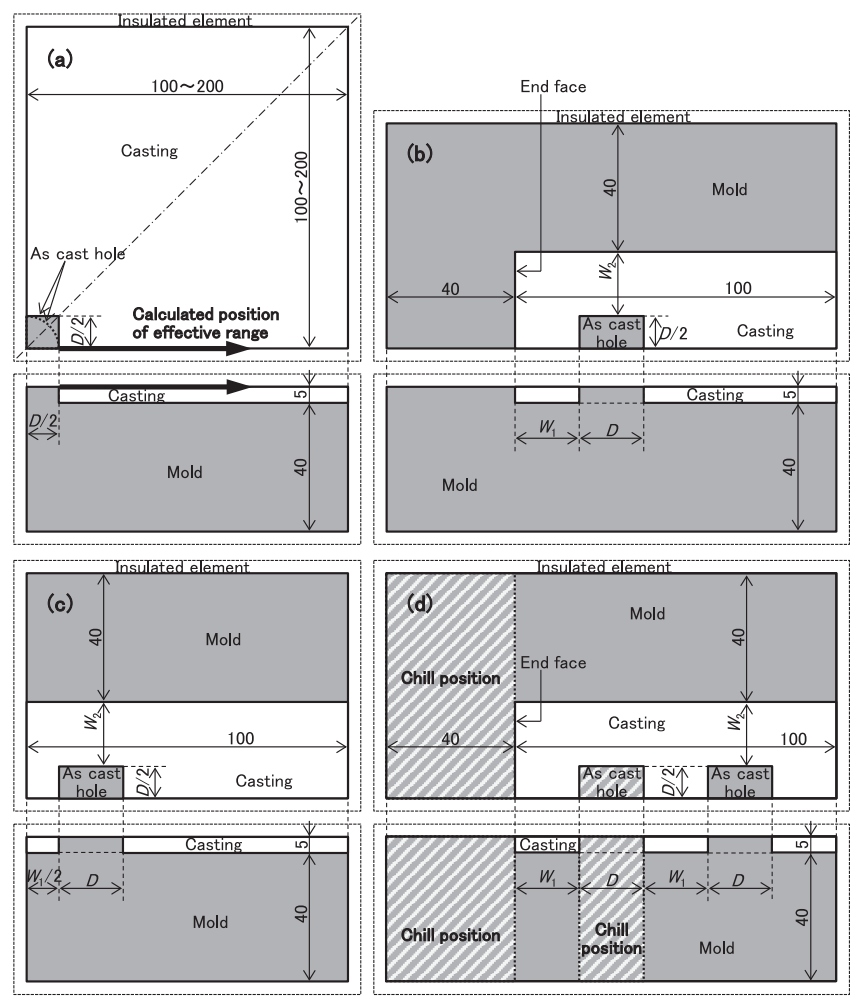

Fig. 2 Schematic view of 3-dimensional simulation models (unit: $\mathrm{mm}$ ). (a) $1 / 8$-symmetric model of infinite plate casting with an as cast hole, (b) 1/4-symmetric model of finite width plate casting with an as cast hole and an end face, (c) 1/8-symmetric model of finite width plate casting with two as cast holes and (d) 1/4-symmetric model of finite width plate casting with two as cast holes and an end face. ments was set to $50 \mathrm{~K}$, except for the case of the semisolid casting of the $\mathrm{AC} 4 \mathrm{C}$ aluminum alloy. The initial temperature of the metal mold was based on the assumption that a die casting process was used. The sand-mold elements were partially replaced by the chill elements as shown in Fig. 2(d) when needed. The interfacial heat resistance between the casting and the mold or chill elements was assumed to be zero. ${ }^{13,14)}$ The heat loss to the air was neglected by surrounding the casting and mold with the insulated elements as shown in Fig. 2. The interfacial heat transfer between the sand mold and chill elements was also neglected.

\subsection{Evaluation of the cooling effects of as cast holes}

In the previous study, the end effects $E / T$ ( $E$ : end-effective range, $T$ : plate thickness) of plate castings were defined by Niyama and Anzai, which reflect the degree of the spontaneous solidification directionality caused by the cooling effect of the end face. ${ }^{13,14)}$ For the plate castings, solidification time along the center plane (maximum solidification time at the distance from the end face) increases with the distance from the end face and then reaches a constant time (solidification time at the infinite distance from the end face). As the range within the cooling effect of the end face, $E$ was defined to be the range where the local solidification time at a certain distance from the end face is less than $97 \%$ of the time at infinite distance from the face. ${ }^{13,14)}$ For cast steel manufactured by sand-mold casting, the experimental value was taken as $E=2.5 T, 3,14-16)$ or the coefficient of 2.5 is the ratio of $E / T .^{13-15)}$ By using the calculated value of $E / T$, the directional solidification characteristics could be easily evaluated and compared. ${ }^{17,18)}$ Similarly, to evaluate the cooling effect of an as cast hole quantitatively, the as cast hole effects $H / T(H$ : as cast hole-effective range) were defined and then calculated from the solidification time distribution. $H$ was assumed to be the range where the local solidification time at a certain distance from the as cast hole is less than $97 \%$ of the time at infinite distance from the hole.

In this study, the transit time of the solidus temperature was used as the solidification time at a certain element. ${ }^{13,14)} H$ was calculated along the line indicated by an arrow shown in Fig. 2(a), for which a sufficiently large plate size of 150 or $200 \mathrm{~mm}$ was prepared. To obtain the solidification time at an infinite distance, a simulation using another infinite plate model without as cast holes was conducted. ${ }^{17,18,20)}$ The value of $E / T$ was also calculated using the same method as in the past study. ${ }^{17,18)}$ Furthermore, for the models shown in

Table 1 Physical properties and initial temperatures for heat transfer and solidification simulation. ${ }^{5-8)}$

\begin{tabular}{|c|c|c|c|c|c|c|c|}
\hline Material & $\begin{array}{l}\text { Density } \\
\left(\mathrm{kg} / \mathrm{m}^{3}\right)\end{array}$ & $\begin{array}{l}\text { Thermal conductivity } \\
\qquad(\mathrm{W} / \mathrm{m} \cdot \mathrm{K})\end{array}$ & $\begin{array}{l}\text { Specific heat } \\
(\mathrm{J} / \mathrm{kg} \cdot \mathrm{K})\end{array}$ & $\begin{array}{l}\text { Latent heat } \\
\qquad(\mathrm{J} / \mathrm{kg})\end{array}$ & $\begin{array}{l}\text { Liquidus temp. } \\
\qquad(\mathrm{K})\end{array}$ & $\begin{array}{l}\text { Solidus temp. } \\
\text { (K) }\end{array}$ & $\begin{array}{l}\text { Initial temp. } \\
\qquad(\mathrm{K})\end{array}$ \\
\hline Cast iron & 7000 & 30 & 670 & 210000 & 1453 & 1413 & 1503 \\
\hline JIS AC4C (ASTM 356.0) & \multirow{2}{*}{2680} & \multirow{2}{*}{151} & \multirow{2}{*}{880} & \multirow{2}{*}{395000} & \multirow{2}{*}{883} & \multirow{2}{*}{828} & 933 \\
\hline Semisolid AC4C & & & & & & & 856 \\
\hline Pure Al & 2688 & 237 & 905 & 395000 & 933 & 932 & 983 \\
\hline Pure $\mathrm{Cu}$ & 8880 & 398 & 386 & 205000 & 1358 & 1357 & 1408 \\
\hline Sand mold & 1500 & 0.6 & 1050 & - & - & - & 293 \\
\hline Metal mold & 7800 & 50 & 500 & - & - & - & 473 \\
\hline Chill & 7800 & 50 & 500 & - & - & - & 293 \\
\hline
\end{tabular}


Figs 2(b), 2(c), and 2(d), the solidification characteristics were systematically evaluated based on the existence or absence of isolated liquid pools during solidification, evidence for which was obtained from the solidification time distribution. The isolated liquid pools often cause shrinkage defects. Although there are other useful shrinkage prediction methods using specific parameters such as the temperature gradient, the NIYAMA parameter, and so on, ${ }^{10,14,19)}$ these methods are likely to be unsuitable for pure metals. ${ }^{19)}$ In contrast, the evaluation of the isolated liquid pools can be applied to both alloys and pure metals alike. ${ }^{17,18,20)}$ In fact, the accuracy of the evaluation was confirmed for pure aluminum. ${ }^{20)}$

\subsection{Fluid flow simulation}

A three-dimensional fluid-flow simulation with consideration of surface tension and temperature changes during mold filling was performed using the commercial software program ADSTEFAN. Subsequently, a simulation of solidification following the mold filling was also performed. Figure 3 shows the casting design of a plate casting with as cast holes and end faces that was used for the simulation. This design was assumed to be the shape shown in Fig. 2(d) under the conditions of $W_{1}=W_{2}=15 \mathrm{~mm}$ with or without chills. The thickness of the chill on the end face was $20 \mathrm{~mm}$. It was assumed that the melt was poured in at a constant rate from the entire upper surface of a cylindrical sprue as shown in Fig. 3. All computational elements were set to be cubic with dimensions of $1 \mathrm{~mm}$ on each side. Table 2 shows the physical properties $^{21)}$ and initial temperatures of the casting and mold materials used in the simulation. The initial superheat of the melt was set at $100 \mathrm{~K}$ by considering the temperature decrease during mold filling. The thermal conductivity of the sand mold was set to $0.8 \mathrm{~W} / \mathrm{m} \cdot \mathrm{K}$, and the interfacial heat resistance between the casting and the mold or chill elements was set at $0.0005 \mathrm{~m}^{2} \cdot \mathrm{K} / \mathrm{W}$, so as to fit the experimental conditions

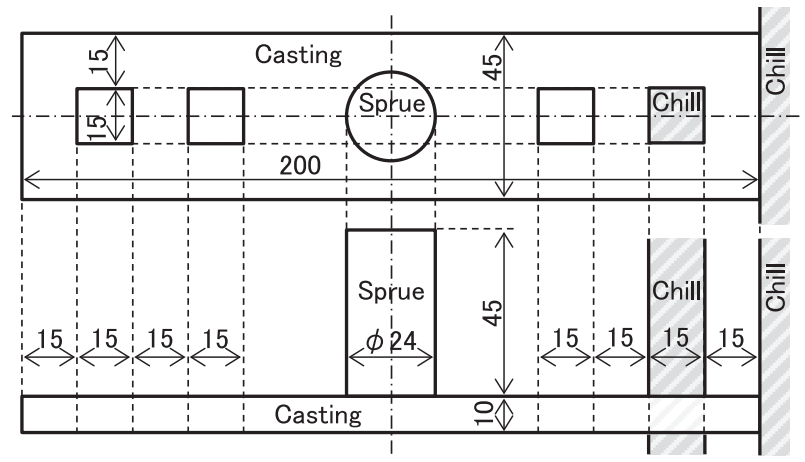

Fig. 3 Schematic view of experimental casting design (unit: $\mathrm{mm}$ ).

Table 2 Physical properties and initial temperatures for fluid-flow simulation. ${ }^{19)}$

\begin{tabular}{ccccc}
\hline Material & $\begin{array}{c}\text { Thermal } \\
\text { conductivity } \\
(\mathrm{W} / \mathrm{m} \cdot \mathrm{K})\end{array}$ & $\begin{array}{c}\text { Kinematic } \\
\text { Viscosity } \\
\left(\mathrm{m}^{2} / \mathrm{s}\right)\end{array}$ & $\begin{array}{c}\text { Surface } \\
\text { tension } \\
(\mathrm{N} / \mathrm{m})\end{array}$ & $\begin{array}{c}\text { Initial } \\
\text { temp. } \\
(\mathrm{K})\end{array}$ \\
\hline JIS AC4C & - & $2 \times 10^{-7}$ & 0.91 & 983 \\
\hline Pure Al & - & $2 \times 10^{-7}$ & 0.91 & 1033 \\
\hline Sand mold & 0.8 & - & - & - \\
\hline
\end{tabular}

in Section 2.4. The inlet velocity of the melt was set so that the filling time was $3.1 \mathrm{~s}$. The other conditions were the same as those shown in Section 2.1.

\subsection{Casting experiment}

The casting design for the experiment is shown in Fig. 3. By using this design, the effect of chills can be compared under exactly the same casting conditions. Pure aluminum ingot (> 99.95\%) was melted using a high-frequency induction furnace and a graphite crucible under atmospheric conditions, and the melt was poured into the mold. The initial superheat and the filling time were the same as those shown in Section 2.3. The sand mold was made from silica sand and water glass by the $\mathrm{CO}_{2}$ process. A plate and a square bar of spheroidal graphite cast iron coated with boron nitride were used as the chill. The casting was cut along the center planes, and then the shrinkage defects or porosity were detected by a dye penetrant test (PT) and observed using an optical microscope. The 3-dimensional distribution of the defects was also analyzed using an X-ray computed tomography (CT) scanner.

\section{Results and Discussion}

\subsection{As cast hole effects in infinite plate castings}

Figure 4 shows the relationship between the calculated as cast hole effects $H / T$ and the relative hole size $D / T$ for the infinite plate model shown in Fig. 2(a). For this case, $H / T=0$ at $D / T=0$ and $H / T=E / T$ at $D / T=\infty$ are assumed. As shown in Fig. 4, in all conditions, $H / T$ monotonically increases with an increase in $D / T$. In the greater range $D / T$ shown in
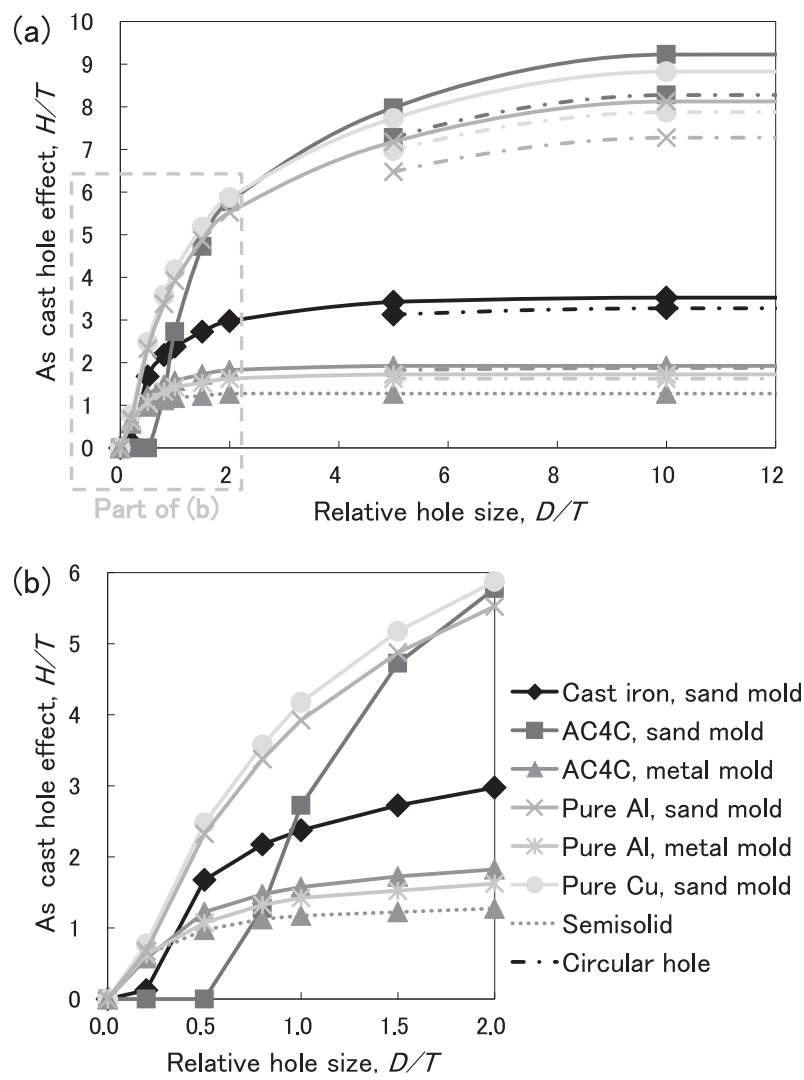

Fig. 4 Relationship between as cast hole effects and relative hole size. (a) Overall and (b) partially enlarged views. 
Fig. 4(a), the relative magnitudes of $H / T$ were the same as those for $E / T$. This result suggests that $H / T$ as well as $E / T$ were affected by both the latent heat of the casting material and the thermal diffusivity ratio between the casting and mold materials, which are the dominant factors for $H / T .^{13,14)}$ In fact, smaller values of $H / T$ and $E / T$ were obtained for the semisolid AC4C than for the other AC4C case, because the latent heat decreased due to the lower initial temperature. For pure metals, for example pure aluminum, smaller values of $H / T$ were obtained than for AC4C. This is mainly because of the latent heat-releasing pattern in the narrower semisolid temperature range. ${ }^{17)}$ In comparison, higher values of $H / T$ were obtained for pure copper than for pure aluminum in spite of the smaller latent heat. This tendency is due to the effect of the greater thermal diffusivity of pure copper. ${ }^{13,14)}$ As a result, there were differences of $H / T$ depending on the hole size and shape, the casting conditions as well as the casting and mold materials.

On the other hand, for the smaller $D / T$ range shown in Fig. 4(b), there were several conditions showing an inversion of the relative magnitudes of $H / T$ with the change of $D / T$, which suggests a change in the dominant factors. In particular, $H / T=0$ was obtained for $\mathrm{AC} 4 \mathrm{C}$, the sand mold and $D / T \leq$ 0.5. A similar pattern was also observed for cast iron. Figure 5 shows the typical solidification time distribution in the model. Comparison of the distributions shows that significantly less solidification directionality from the hole was observed for $\mathrm{AC} 4 \mathrm{C}$, the sand mold and $D=5 \mathrm{~mm}(D / T=0.5)$ as shown in Fig. 5(a). This pattern reflects significantly less cooling effects due to the hole or $H / T=0$, which is mainly caused by the greater temperature increase of the core part for a comparatively longer solidification time. In comparison, skin-formation-type solidification sequences were observed for the metal mold shown in Figs. 5(c) and 5(d) as well as for
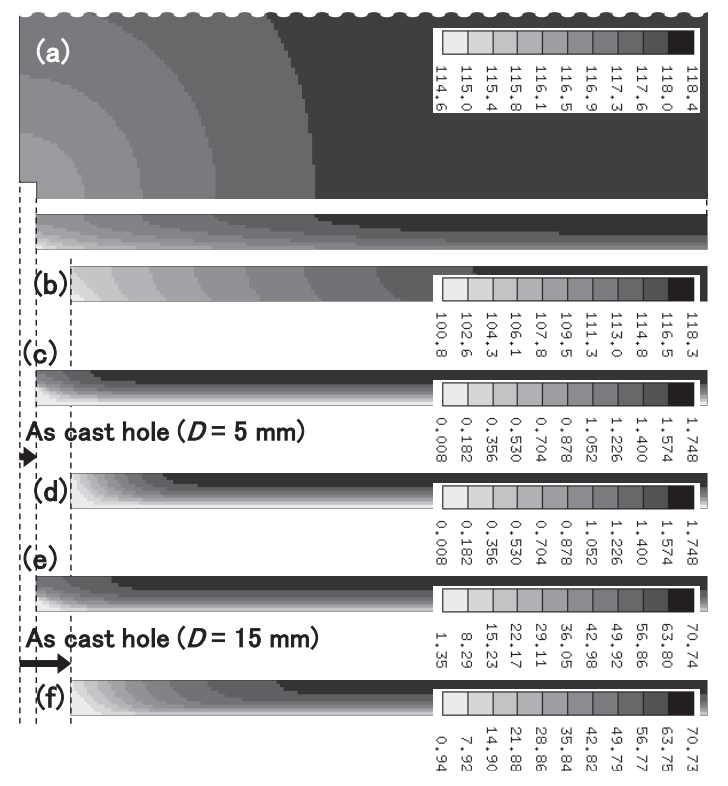

Fig. 5 Solidification time distribution in infinite plate castings with an as cast hole (scale: minimum-maximum, unit: s). (a) AC4C, sand mold, $D / T=0.5(H / T=0.00)$, (b) AC4C, sand mold, $D / T=1.5(H / T=4.73),(\mathrm{c})$ AC4C, metal mold, $D / T=0.5(H / T=1.23)$, (d) AC4C, metal mold, $D / T=$ $1.5(H / T=1.73)$, (e) Pure Al, sand mold, $D / T=0.5(H / T=2.33)$ and (f) Pure Al, sand mold, $D / T=1.5(H / T=4.88)$. the pure metals shown in Figs. 5(e) and 5(f). In contrast to Figs. 5(a) and 5(b), the sequences indicate that there is smaller solidification directionality from the hole despite the differences in the hole size. As for the metal mold, Fig. 4 also shows the tendency that the changes of $H / T$ with respect to $D / T$ are relatively smaller than for the sand mold. This is because solidification of the entire casting has finished due to the stronger cooling effect of the metal mold before reaching the cooling effect of the hole as shown in Figs. 5(c) and 5(d), which is called stronger "locality in solidification." ${ }^{9,22)}$ Consequently, $H / T$ corresponds to the particular solidification directionality associated with the cooling effects due to the hole. This indicates that the directional solidification characteristics can be quantitatively evaluated and compared by using $H / T$.

Figure 4(a) also shows the results for the circular hole. As shown in Fig. 4(a), slightly smaller values of $H / T$ were observed for the circular hole than for the square hole. The smaller values are a result of the smaller volume and/or smaller heat-exchange surface area of the circular core part, suggesting that the general tendencies are almost the same as those for the square hole. In the literature, there are several design concepts for a circular hole in a plate casting, which recommend $D \geq T / 2$ and $D \geq 10 \mathrm{~mm}$ for cast iron, or $D \geq T$ and $D \geq 20 \mathrm{~mm}$ for cast steel. ${ }^{3)}$ For die casting processes, although the design depends on both the casting material and the value of $D$, the recommendations of $2.5 D \geq T$ and $D \geq$ $3 \mathrm{~mm}$ are, on the whole, suitable for such metals as aluminum alloys. ${ }^{3)}$ Conditions outside of these ranges may adversely affect the solidification pattern, resulting in a greater temperature increase in the core. In addition, a wider range of values is recommended for die casting processes than for cast iron and cast steel, which suggests that comparatively stronger cooling effects due to the small hole are present for die casting processes than exist for sand-mold casting. These imply the accuracy of the tendencies of $H / T$ obtained by the simulation.

\subsection{Solidification characteristics in finite-width plate castings with an as cast hole and an end face}

Figure 6 shows the typical solidification time distribution in the finite-width plate model with an as cast hole and an end face shown in Fig. 2(b). As shown in Fig. 6(a), there were conditions where no generation of an isolated liquid pool occurred in the solidification time distribution. On the other hand, isolated liquid pools were observed between the hole and the end face as shown in Figs. 6(b) and 6(c) under the specified conditions. The positions where the isolated liquid pools are generated are classified into two categories: "center" and "side" as shown in Figs. 6(b) and 6(c), respectively. Due to the partial representation of the symmetric shape, the "center" and "side" positions correspond the generation of one and two isolated liquid pools, respectively.

Figure 7 shows the typical relationship between the generation status of the isolated liquid pools and the relative widths $W_{1} / T$ and $W_{2} / T$ in the model. The generation status shown in Fig. 7 reflects the general tendency that greater $W_{1}$ and/or smaller $W_{2}$ cause the isolated liquid pools, which suggests the existence of a minimum width ratio of $W_{1}$ and $W_{2}$ for which an isolated liquid pool is not generated. As a result, there were 

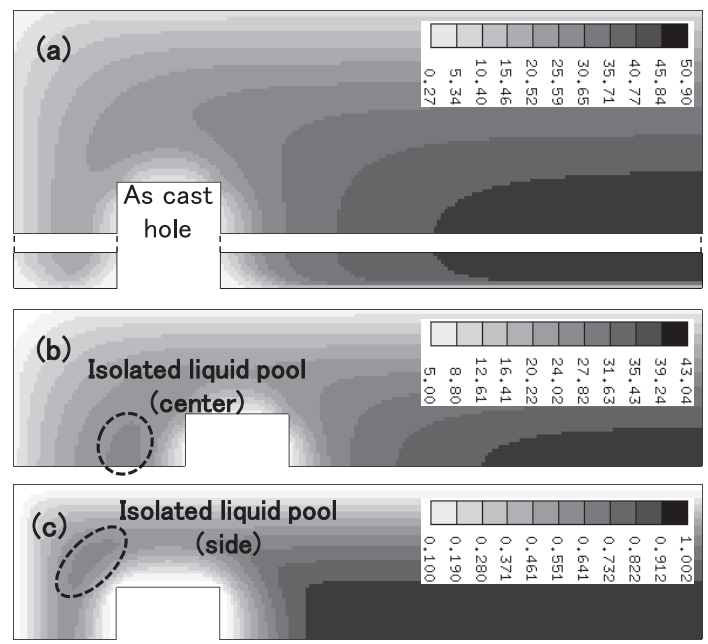

Fig. 6 Solidification time distribution in finite-width plate castings with an as cast hole and an end face (pure $\mathrm{Al}, D=15 \mathrm{~mm}$, unit: $\mathrm{s}$ ). (a) Sand mold, $W_{1}=15 \mathrm{~mm}, W_{2}=25 \mathrm{~mm}$, (b) sand mold, $W_{1}=25 \mathrm{~mm}, W_{2}=15 \mathrm{~mm}$ and (c) metal mold, $W_{1}=15 \mathrm{~mm}, W_{2}=15 \mathrm{~mm}$.
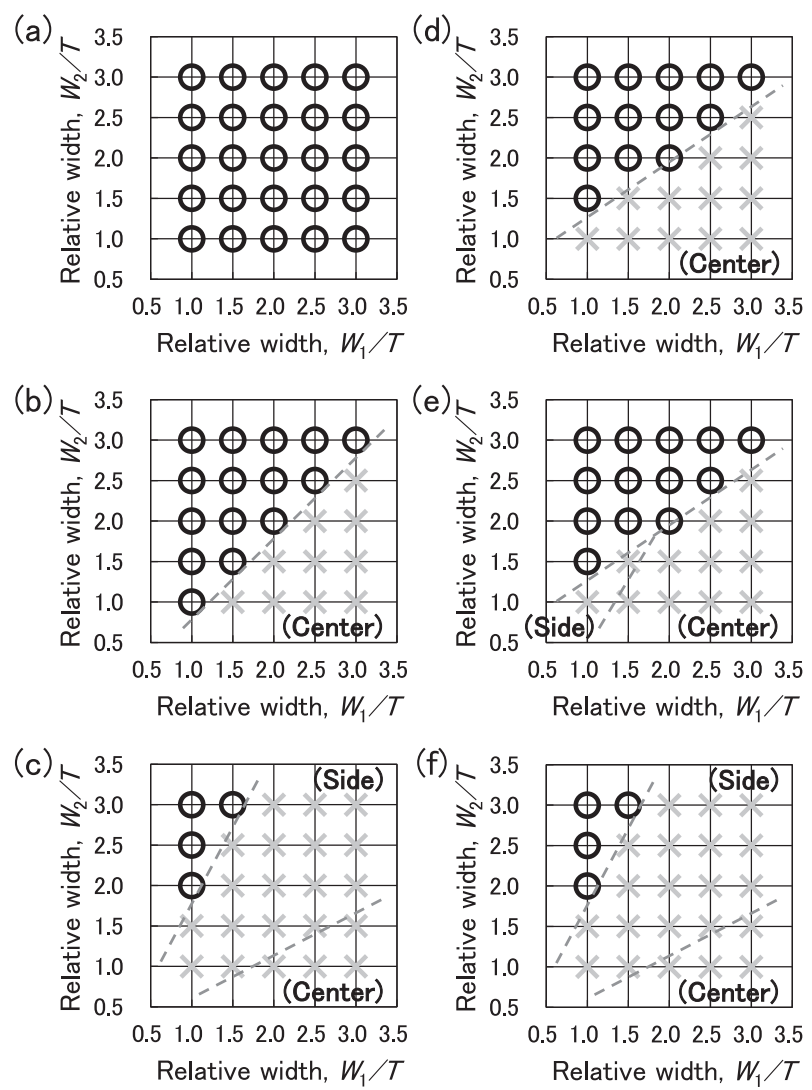

Fig. 7 Relationship between generation status of isolated liquid pools and relative widths in finite width plate casting with an as cast hole and an end face $(\bigcirc$ : without isolated liquid pools, $\times$ : with isolated liquid pools). (a) AC4C, sand mold, $D / T=0.5(H / T=0.00)$, (b) AC4C, sand mold, $D / T=$ $1.5(H / T=4.73),(\mathrm{c})$ AC4C, metal mold, $D / T=1.5(H / T=1.73),(\mathrm{d})$ pure Al, sand mold, $D / T=0.5(H / T=2.33)$, (e) pure Al, sand mold, $D / T=1.5$ $(H / T=4.88)$ and (f) pure Al, metal mold, $D / T=1.5(H / T=1.53)$.

differences in the generation status depending on the casting and mold materials and the hole size. For the metal mold, a wider "side" range was obtained as shown in Figs. 7(c) and 7(f) despite the different casting materials. This is also because of the stronger cooling effect of the metal mold. How-

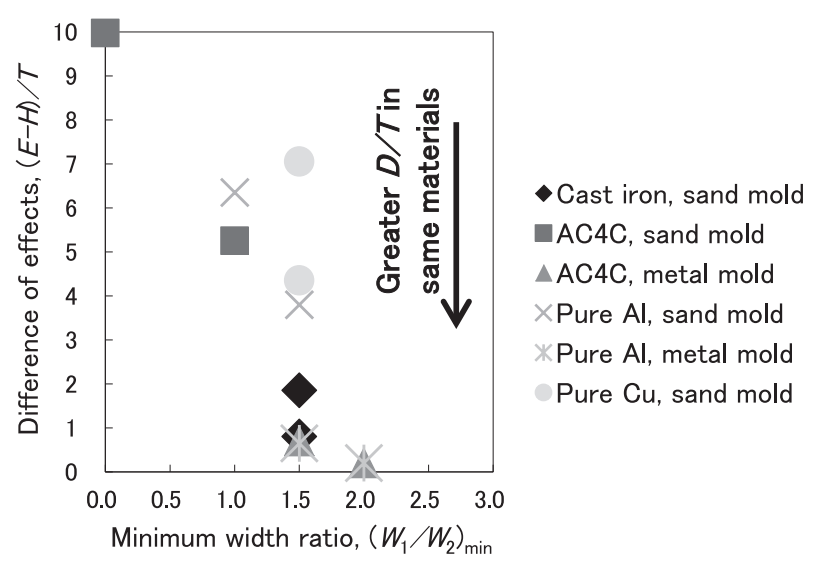

Fig. 8 Relationship of the difference between the end and as cast hole effects to the minimum width ratio without isolated liquid pools in finite-width plate casting with an as cast hole and an end face $(D / T=0.5$, $1.5)$.

ever, in contrast to the generation status for pure aluminum shown in Fig. 7(d), there was only one range without generation of an isolated liquid pool in the status for AC4C, sand mold and $D / T=0.5$ shown in Fig. 7(a). These results indicate that not only $H / T$ but also other factors affected the generation status. The generation positions shown in Figs. 6(b) and 6(c) suggest that at least one of the factors is $E / T$.

Figure 8 shows the relationship of the difference between the end and as cast hole effects $(E-H) / T$ to the minimum width ratio without an isolated liquid pool, referred to as $\left(W_{1} / W_{2}\right)_{\min }$, in the model. Here, smaller value of $\left(W_{1} / W_{2}\right)_{\min }$ indicates the existence of a wider range of that parameter without generation of an isolated liquid pool in the generation status shown in Fig. 7. As shown in Fig. 8, the generation of isolated liquid pools can be prevented by the condition expressed by $W_{1} / W_{2} \geq 2$. In comparison, an inverse relationship between $(E-H) / T$ and $\left(W_{1} / W_{2}\right)_{\min }$ was observed, indicating that greater $E / T$ and/or smaller $H / T$ are preferred. This tendency suggests that the generation of isolated liquid pools occurs when the directional solidification from the end face is prevented by the hole. Accordingly, conditions with greater values of $(E-H) / T$ are preferable for preventing the generation of isolated liquid pools.

\subsection{Solidification characteristics in finite-width plate castings with two as cast holes}

Figure 9 shows the typical relationship between the generation status of isolated liquid pools and $W_{1} / T, W_{2} / T$ in the finite-width plate model with two as cast holes shown in Fig. 2(c). In the model, isolated liquid pools were observed in the area between the holes under the specific conditions. The generation positions of the isolated liquid pools are also classified into "center" and "side" categories, for which the locations are the same as for the model shown in Figs. 6(b) and 6(c). In comparison with the generation status shown in Fig. 7 with the same casting and mold materials and value of $D / T$, it is apparent that wider "center" and/or "side" ranges were obtained for the model as shown in Fig. 9. In particular, there was only a "center" range in the status for the conditions involving $\mathrm{AC} 4 \mathrm{C}$, a sand mold and $D / T=0.5$ shown in Fig. 9(a) despite a value of $H / T=0$. In comparison, for the metal mold, 
a wider "side" range was obtained as shown in Fig. 9(d).

Figure 10 shows the relationship between $(E-H) / T$ and $\left(W_{1} / W_{2}\right)_{\min }$ in the model. Where $\left(W_{1} / W_{2}\right)_{\min }>3.0$, the conditions are such that it is almost impossible to prevent the generation of isolated liquid pools for the conditions with smaller $W_{1}$ and/or greater $W_{2}$. As shown in Fig. 10, values of $\left(W_{1} / W_{2}\right)_{\min }>3.0$ were obtained under most conditions. For the condition with values of $\left(W_{1} / W_{2}\right)_{\min }>3.0$ with greater values of $(E-H) / T$, only a "center" range was observed. In contrast to the relationship shown in Fig. 8, this tendency more strongly reflects the across-the-width cooling effect based on greater values of $E$ and smaller values of $H$. Similarly, a wider "center" range with a narrower "side" range was also observed for $\mathrm{AC} 4 \mathrm{C}$, a sand mold and $D / T=1.5$, as shown in Fig. 9(b), due to the comparatively greater value of $(E-H) / T$. On the other hand, for the condition where $\left(W_{1} / W_{2}\right)_{\min }>3.0$ with smaller values of $(E-H) / T$, a wider
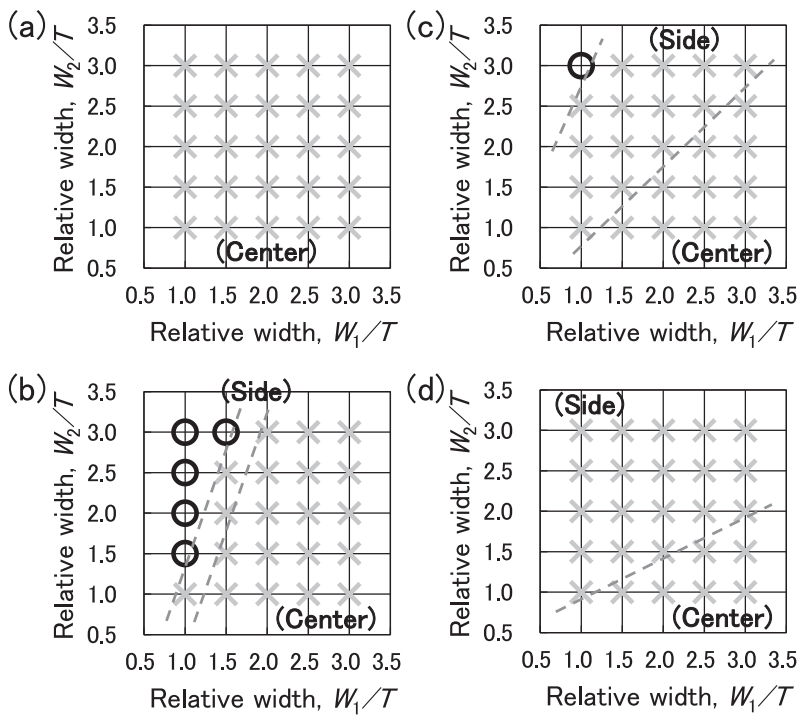

Fig. 9 Relationship between the generation status of isolated liquid pools and relative widths in finite-width plate casting with two as cast holes $(\mathrm{O}$ : without isolated liquid pools, $\times$ : with isolated liquid pools). (a) AC4C, sand mold, $D / T=0.5((E-H) / T=9.98)$, (b) AC4C, sand mold, $D / T=1.5$ $((E-H) / T=5.25)$, (c) pure Al, sand mold, $D / T=1.5((E-H) / T=3.80)$ and (d) pure Al, metal mold, $D / T=1.5((E-H) / T=0.20)$.

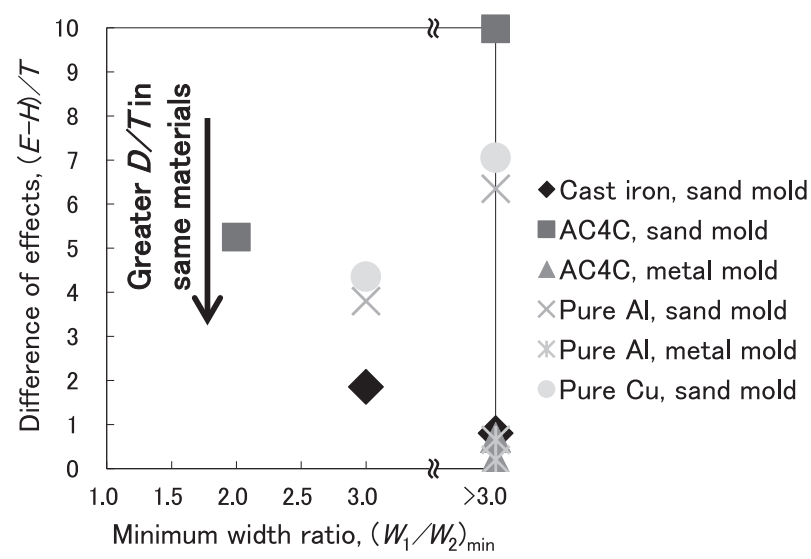

Fig. 10 Relationship of the difference between end and as cast hole effects to the minimum width ratio without isolated liquid pools in finite-width plate casting with two as cast holes $(D / T=0.5,1.5)$. "side" range was observed. This is because the "side" positions become hot spots due to an unfavorable balance between $E$ and $H$, as seen in the T-junction shape. ${ }^{9,18)}$ In fact, for a metal mold, $\left(W_{1} / W_{2}\right)_{\min }>3.0$ with smaller values of $(E-H) / T$ was obtained, as expected, due to the stronger cooling effect of the mold. Accordingly, the conditions with values of $(E-H) / T$ in the range of 1.8-5.3 with sufficiently large values of $\left(W_{1} / W_{2}\right)_{\min }$ are preferred for preventing the generation of liquid pools. Otherwise, the addition of sufficient longitudinal solidification directionality using techniques such as chills may be preferable on the basis of the generation mechanisms of the isolated liquid pools.

\subsection{Solidification characteristics in finite-width plate castings with two as cast holes and an end face}

Figure 11 shows the typical solidification time distribution in the finite-width plate model with two as cast holes and an end face shown in Fig. 2(d). For pure aluminum, a sand mold and $D=W_{1}=W_{2}=15 \mathrm{~mm}$ shown in Fig. 11(a), "side" isolated liquid pools were observed both near the end face and between the holes. Each generation pattern was also the same as that in the models shown in Figs. 2(b) and 2(c), which were shown in Figs. 7(e) and 9(c), respectively. This could be confirmed in a number of other conditions. On the other hand, for AC4C and $D=5 \mathrm{~mm}$, the generation of an isolated liquid pool located in the "center" between the holes can be similarly predicted on the basis of the generation status shown in Figs. 7(a) and 9(a). In fact, however, an isolated liquid pool was not observed, as shown in Fig. 11(b). This suggests that
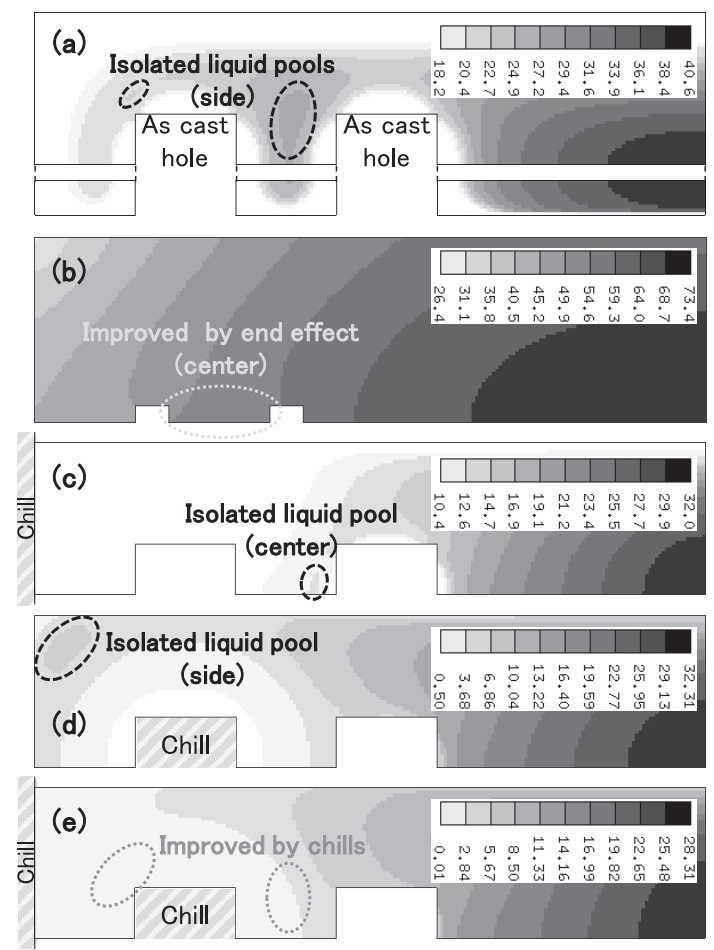

Fig. 11 Solidification time distribution in finite-width plate castings with two as cast holes and an end face (sand mold, $W_{1}=15 \mathrm{~mm}$, unit: $\mathrm{s}$ ). (a) Pure Al, $D=15 \mathrm{~mm}, W_{2}=15 \mathrm{~mm}((E-H) / T=3.80)$, (b) AC4C, $D=$ $5 \mathrm{~mm}, W_{2}=25 \mathrm{~mm}((E-H) / T=9.98)$, (c) pure Al, $D=15 \mathrm{~mm}, W_{2}=$ $15 \mathrm{~mm}$, using a chill (end face), (d) pure Al, $D=15 \mathrm{~mm}, W_{2}=15 \mathrm{~mm}$, using a chill (as cast hole) and (e) pure Al, $D=15 \mathrm{~mm}, W_{2}=15 \mathrm{~mm}$, using both chills. 
the "center" isolated liquid pool between the holes was improved by the larger values of $E / T$ for $\mathrm{AC} 4 \mathrm{C}$ and a sand mold. Accordingly, the generation pattern in the model corresponds to the superimposed generation status in both the model with an as cast hole and an end face, and the model with two holes.

Figure 12 shows the relationship between $(E-H) / T$ and $D / T$. The preferred range and conditions based on Figs. 8 and 10 are shown in Fig. 12, which indicate that the conditions with larger values of $(E-H) / T$ in the range of 1.8-5.3 are preferred for preventing the generation of isolated liquid pools in the model. Specifically, for AC4C, pure aluminum, or pure copper and a sand mold, greater values of $D / T$ are preferred, as seen in Fig. 12. In comparison, for cast iron and a sand mold or for a metal mold, smaller values of $D / T$ are preferred. Thus, consideration of the values of $(E-H) / T$ is useful as fundamental concepts for preventing the generation of shrinkage defects around the holes. If it is possible to control the physical properties of the core parts that depend on such variables as casting and mold materials, creating as cast holes without generating shrinkage defects might be possible.

Figures 11(c), 11(d), and 11(e) show the typical solidification time distribution in the model shown in Fig. 2(d) using chills. These improvement ideas are based on the above-mentioned insights, which show that it is possible to prevent the generation of isolated liquid pools by using a stronger cooling effect at the end face and/or the addition of across-the-width solidification directionality between the holes. As shown in Figs. 11(c) and 11(d), the generation of the isolated liquid pools seen in Fig. 11(a) was not eliminated by applying a chill to the end face and in a core part, respectively. For the condition of a chill on the end face, generation of only a "center" isolated liquid pool was observed between the holes as shown in Fig. 11(c), suggesting less longitudinal solidification directionality there. In comparison, for the condition of a chill in a core part, generation of only a "side" isolated liquid pool was observed near the end face as shown in Fig. 11(d), suggesting a relatively smaller cooling effect from the face. This condition may be due to a negative value of $(E-H) / T$, which corresponds to the generation pattern shown in Fig. 8. On the other hand, for the condition with both chills, the generation of liquid pools was prevented by adequate cooling as shown in Fig. 11(e). Similar patterns were confirmed for the $\mathrm{AC} 4 \mathrm{C}$ case. In conjunction with the information shown in

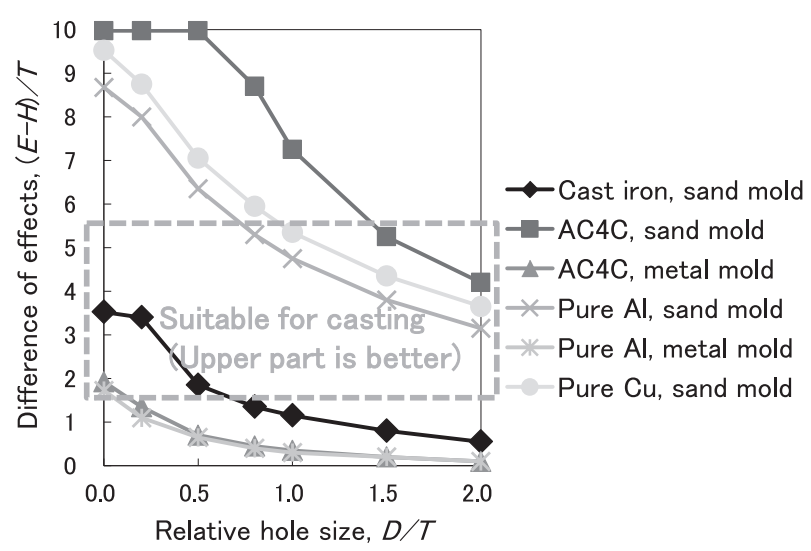

Fig. 12 Relationship of the difference between the end and as cast hole effects to the relative hole size.
Fig. 12, these results indicate that the generation of isolated liquid pools could be prevented by the adequate use of chills despite the absence of a small shape restriction.

\subsection{Solidification pattern considering the mold-filling process}

Figure 13 shows the solidification time distribution with consideration of the mold-filling process for the experimental casting design shown in Fig. 3. For AC4C and the side without chills, the generation of an isolated liquid pool in the "center" between the holes is predicted based on the generation status shown in Figs. 7(b) and 9(b). In fact, the generation was observed as shown in Fig. 13(a). Similarly, for pure aluminum, the generation of "side" isolated liquid pools near the end face and between holes can be predicted as it is for Fig. 11(a). However, the generation of only "side" isolated liquid pools between the holes was observed as shown in Fig. 13(b). Other simulation results confirmed that both the thermal conductivity of the mold and the interfacial heat resistance between the casting and the mold elements used in this section did not affect the generation status. Accordingly, this suggests that the generation was partly prevented by an increase in across-the-width solidification directionality due to the melt temperature decrease during mold filling. Furthermore, for the side with chills, all generation was prevented as shown in Fig. 13. These results verified that the above-mentioned techniques indicate the correct policies on the side of prudence for the casting design to prevent the generation of isolated liquid pools.

Figure 14 shows the X-ray CT images, PT results and an optical micrograph of a horizontal cross-section along the center plane in the experimental casting of pure aluminum. In fact, as shown in Figs. 14(a) and 14(c), the generation of shrinkage defects was detected at the positions of the "side" isolated liquid pools seen in Fig. 13(b), which appears as spherical porosity as shown in Fig. 14(a) and 14(e). In com-

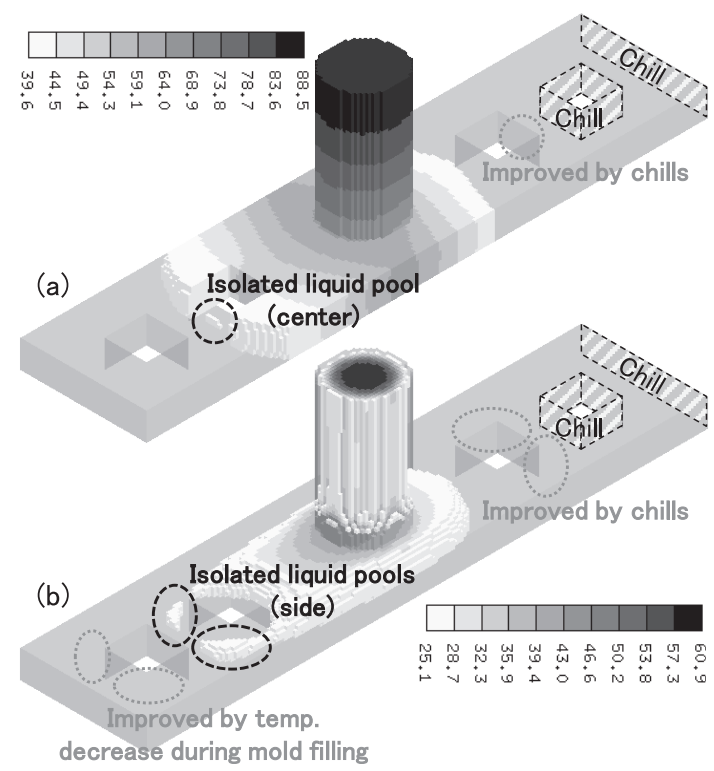

Fig. 13 Solidification time distribution with consideration of mold-filling process in experimental casting design (sand mold, unit: s). (a) AC4C and (b) pure Al. 

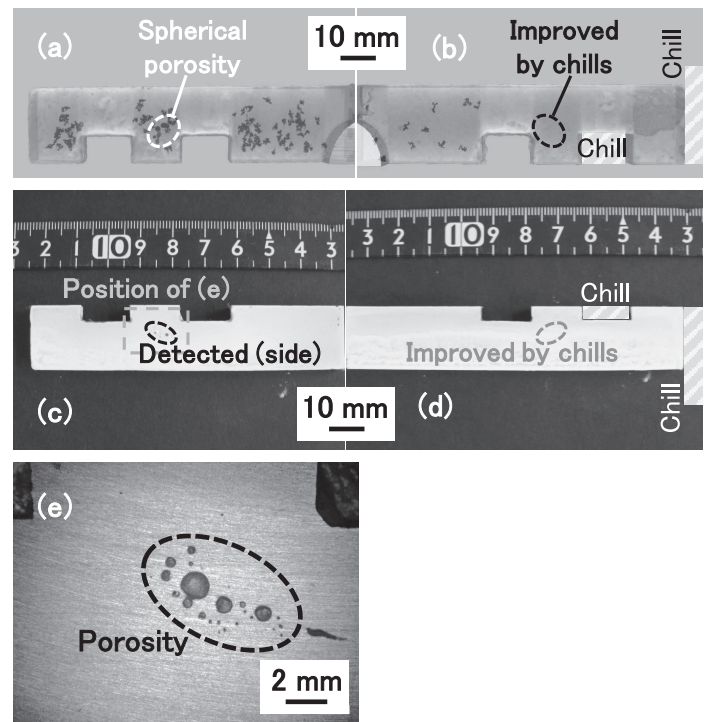

Fig. 14 (a), (b) X-ray CT images (porosity of more than $0.6 \mathrm{~mm}^{3}$ is black), (c), (d) PT results and (e) optical micrograph of horizontal cross-section along center plane in experimental casting (pure Al).

parison, the defects were improved by the use of chills as shown in Fig. 14(b) and 14(d). Thus, the effectiveness of the preventive techniques applied to the simulation results was experimentally confirmed.

\section{Conclusions}

The directional solidification characteristics and the generation pattern of isolated liquid pool in plate castings with as cast holes were numerically examined, and fundamental concepts for the casting design including the holes were also investigated. In addition, the effectiveness of the measures for eliminating the generation of shrinkage defects was experimentally confirmed. The following conclusions were obtained from this study.

(1) For the as cast hole effects characterized by $H / T$, differences depend on the hole sizes and shapes and casting conditions, as well as on the casting and mold materials. These reflect the directional solidification characteristics associated with the cooling effects due to the hole.

(2) For the finite-width plate castings with an as cast hole and an end face, isolated liquid pools occur between the hole and the end face under specific conditions.

(3) For the finite-width plate castings with two as cast holes, isolated liquid pools are generated between the holes under a large number of conditions. Conditions with values of $(E-H) / T$ in the range of 1.8-5.3 are preferable for preventing the generation of isolated liquid pools.

(4) For the finite-width plate castings with two as cast holes and an end face, the generation pattern of isolated liquid pools can be explained as a combination of both the generation pattern in the cases with an as cast hole and an end face, and the generation pattern in the case with two as cast holes. As a result, consideration of the value of $(E-H) / T$ is a useful criterion for the casting.

(5) The generation of isolated liquid pools is prevented by the adequate use of chills. The generation is also occasionally prevented by a temperature decrease of the melt during mold filling.

\section{Acknowledgments}

The authors would like to thank F. Uchida, K. Kurosawa (Akita Industrial Technology Center), and K. Tomita (Graduate School of Engineering Science, Akita University) for providing the technical support for the experiment, and Enago (www.enago.jp) for the English language review.

\section{REFERENCES}

1) T. Ohuchi: J. JFS, Inc. 9 (2013) 5410-5416.

2) J. Yaokawa, D. Miura, K. Anzai, Y. Yamada and H. Yoshii: Mater. Trans. 48 (2007) 1034-1041.

3) Japan Foundry Engineering Society: Chuzo-kogaku-binran, (Maruzen, Tokyo, 2002) pp. 13, 37-38.

4) Japan Die Casting Association: Die Cast-tte-nani? - DIE CASTING-, (Japan Die Casting Association, Tokyo, 2003) p. 31.

5) S. Takeda and S. Orii: JJILM 66 (2016) 124-129.

6) E. Niyama: J. JFS 73 (2001) 747-752.

7) The Japan Society of Mechanical Engineers: JSME Data Book: Heat transfer, (Maruzen, Tokyo, 1986) pp. 314, 318.

8) The Japan Institute of Metals: Kinzoku Data Book, (Maruzen, Tokyo, 2004) p. 369.

9) E. Niyama: J. JFS 74 (2002) 177-181.

10) I. Takahashi, T. Uchida and K. Anzai: J. JFS 78 (2006) 661-667.

11) I. Goto, S. Horiuchi and K. Anzai: Int. J. Cast Met. Res. 24 (2011) 243-246.

12) I. Goto, K. Anzai and S. Ideguchi: Q. J. Jpn. Weld. Soc. 30 (2012) 345-353.

13) E. Niyama and K. Anzai: IMONO 66 (1994) 31-37.

14) E. Niyama: Chuzo-dennetsu-kogaku, (Agne Gijutsu Center, Tokyo, 2001) pp. 97-98, 124, 127-138.

15) H.F. Bishop and W.S. Pellini: Trans. Am. Foundrymen's Soc. 58 (1950) 185-197.

16) P. Belley: Foundry Technology, (Butterworth-Heinemann, Oxford, 2001) p. 137.

17) I. Goto and S. Aso: J. JFS 85 (2013) 745-752.

18) I. Goto and S. Aso: J. JFS 87 (2015) 109-116.

19) I. Nakajima: Reports of the 139th JFS Meeting (2001) p. 12

20) I. Goto, S. Aso, K. Anzai and S. Ideguchi: J. JFS 87 (2015) 439-445.

21) N. Kayama: Imono-no-ohanashi, (Japanese Standards Association, Tokyo, 1985) pp. 17, 19.

22) I. Goto, S. Aso, K. Anzai and S. Ideguchi: J. JFS 86 (2014) 3-11. 